\title{
Studying the psychology of coping negative emotions during COVID-19: a quantitative analysis from India
}

\author{
Vishal Pandey ${ }^{1} \cdot$ Amogh Talan $^{2} \cdot$ Mandeep Mahendru ${ }^{3,4}$ (D) $\cdot$ Umer Shahzad $^{5}$ (D) \\ Received: 5 June 2021 / Accepted: 12 August 2021 / Published online: 16 September 2021 \\ (C) The Author(s), under exclusive licence to Springer-Verlag GmbH Germany, part of Springer Nature 2021
}

\begin{abstract}
The outbreak of the COVID-19 virus adversely affected the material and mental well-being of the infected individuals and their families. The poor health system combined with lack of fear of infection has created significant negative health effects for people. The present research consider the notable models of coping with negative emotions, including '3Cs' and 'direct action and palliation approach'. With the observation method's help, a detailed perspective was found on people's coping processes, categorized as psychological, control, coherence, and connectedness coping. The present study considers the notable models of dealing with negative feelings, including ' $3 \mathrm{Cs}$ ' and 'direct intervention and palliation strategy'. With the observation method's support, a detailed viewpoint was found on people's coping mechanisms, categorized as neurological, regulation, coherence, and connectedness coping. Using the ANOVA and t-tests, a significant augmentation in people's negative emotions was found since the beginning of the pandemic. Using GMM regression technique, 'avoidance', 'proactive preparedness', 'emotional resilience', 'entertainment', and 'spiritualism' were highly significant techniques in curbing the negative emotions during the COVID-19 pandemic. Meanwhile, the LOGIT regression found cumulative negative emotions and emotions about negative career outlooks to be the most significant to bring negative emotions to normalcy. The study suggests that policymakers design a national-level strategy to strengthen the mental health systems to boost mental well-being.
\end{abstract}

Keywords COVID-19 $\cdot$ Negative emotions · Coping strategies $\cdot$ Quantitative $\cdot$ LOGIT regression

\section{Highlights}

- This study considers the notable models of coping with negative emotions during the pandemic.

- Survey data from the residents of India is utilized.

- The study employed GMM and logistic (LOGIT) regression for empirical analysis.

- Avoidance, proactive preparedness, and entertainment might be helpful in curbing the negative emotions during the COVID-19 pandemic.

Responsible Editor: Lotfi Aleya

Mandeep Mahendru

mandip129@gmail.com

Umer Shahzad

Shehzad-umer@hotmail.com; umer@aufe.edu.cn

Vishal Pandey

pandey.vishal@icai.org

Amogh Talan

amoghtalan@gmail.com
1 Department of Commerce, Ramjas College, University of Delhi, University Enclave, Delhi 110007, India

2 Department of Commerce, College of Vocational Studies, University of Delhi, Triveni, Sheikh Sarai-II, New Delhi 110017, India

3 State Bank Institute of Leadership, Kolkata, India

4 State Bank Institute of Credit and Risk Management, Gurugram, India

5 School of Statistics and Applied Mathematics, Anhui University of Finance and Economics, Bengbu 233030, People's Republic of China 


\section{Introduction}

The coronavirus disease (COVID-19) emerged in Wuhan city of China in December 2019. As of August 5, 2021, this virus has infected 201,817,159 people and causing 4,283,757 deaths globally (Worldmeter 2021; Fareed et al. 2020). The exponential rise in the novel coronavirus (COVID-19) cases in the world developed into a pandemic (Dennison Himmelfarb and Baptiste 2020). It was declared a pandemic by the World Health Organization on March 11, 2020, considering its contagious behaviour (Saey 2020; Shahzad et al. $2020 \mathrm{a}, \mathrm{b})$. India is among one of the worst-hit countries. People are affected financially and emotionally by this virus (Yan et al. 2021). Therefore, the present study aims to observe the negative emotional states during the COVID-19 pandemic, and how such emotions change with time during the pandemic, the kind of coping mechanisms people adopt to deal with negative emotions, and which of these coping strategies prove to be most successful in alleviating the negative emotions

This virus spreads rapidly; it transmits directly or indirectly when people are in close contact with an infected person or sneezes or coughs by an infected person (Shahzad et al. 2021; Sarwar et al. 2021). Everyday lives of the people have substantially changed, and these have been replaced by isolation and loneliness (Shakoor et al. 2020; Shahzad et al. 2020b). Social activities like school, cinema halls, and work have been suspended because of the threat of the spread of this virus. The absence of social interactions has led to overwhelming stress, depression, a state of panic, anxiety, mental instability, and reluctance to work both at individual and community levels (Brooks et al. 2020; Iqbal et al. 2020).

COVID-19-like pandemic is unlike in modern years, and there is no magic formula established to resolve the sociopsychological trauma it induces. Societies as a whole and individuals, in general, have various tactics to deal with this condition. Recent research is done so far on the coping mechanisms for the distress caused by natural disasters, and pandemics have come up with a few theories such as the '3Cs' model of Reich (2006) or Lazarus's (1985) 'direct action' and 'palliation' approach which entails different mechanisms of coping. The present research discusses general population shifts in stress-related emotions since the pandemic's initial spread. Further, the efficacy of individuals' coping mechanisms in combating negative feelings has been analysed.

The prominent stress-related emotions, such as stress, worry, hopelessness, bleak economic, career, social outlooks, and a general feeling that things will never be the same again are prevalent among masses due to the pandemic. With the constant spread of COVID-19 and having an uncertain timeline for treatment, against all odds, people steadily return to their 'new' normal and contemplate the dynamic psychology of the human mind, which evolves and adapts to an adverse circumstance and continues to see it as 'normal'; it would be interesting to observe the trend of the negative psychological pattern since the beginning of the COVID-19 pandemic.

The pandemic coping strategies can be classified into various subgroups. As per the '3Cs' model of Reich (2006), preparedness strategies, entertainment interventions, and scenario avoidance may be e categorized as 'control' approaches. Although meditative techniques and spiritualism and participation in constructive practices can be classified as the "coherence' approach, social support can be classified as a 'connectedness' approach. However, be it the ' $3 \mathrm{Cs}$ ' model or Lazarus's (1985) 'direct action' and 'palliation' approach, neither of them recognizes the inherent capacity of the human mind to cope with a complicated and stressful situation. Such mental ability to cope ranges from individual to person, where a person can be considered 'mentally strong' if he has a better ability to endure a highly stressful situation. We incorporate two such core mental abilities to resolve negative states, namely 'emotional resilience' described as 'the process of, capacity for, or outcome of successful adaptation despite challenging or threatening circumstances' (Masten et al. 1991) and 'optimism' defined as 'a set of beliefs that leads people to approach the world actively' (Peterson and Bossio 1991).

The research aims to study the role and significance of coping strategies in abating negative emotions during these times. The framework of the objectives of the study is presented in Fig. 1. The study has taken seven factors of the negative emotions, i.e. stress, worry, hopelessness, non-normality, bleak economic outlook, bleak career outlooks, and bleak social outlooks, and four coping categories, i.e. psychological coping, control coherence copying, and connectedness coping. Coping mechanisms affect negative emotions of the people. Therefore, the present study analyses the following: firstly, the impact of behavioural effect of the people during pandemic on the negative emotions; secondly, how adverse behavioural changes effects on negative emotions; thirdly, the impact of coping strategies on negative emotions (Kar et al. 2021); and lastly, can the control of adverse behaviour during the pandemic with coping strategies bring normalcy to the behaviour (Shamblaw et al. 2021).

To achieve our objectives, the following hypotheses were framed:

$\mathrm{H}_{1}$ : There is a behavioural effect during COVID-19 pandemic in dependent variables (negative emotions).

$\mathrm{H}_{2}$ : There are adverse behavioural changes during COVID-19 pandemic in dependent variables (negative emotions).

$\mathrm{H}_{3}$ : Independent variables (coping strategies) affect dependent variables (negative emotions).

$\mathrm{H}_{4}$ : Control of adverse behaviour during the pandemic with independent variables (coping strategies) can bring normalcy in the behaviour. 
Fig. 1 Framework of emotions and COVID-19

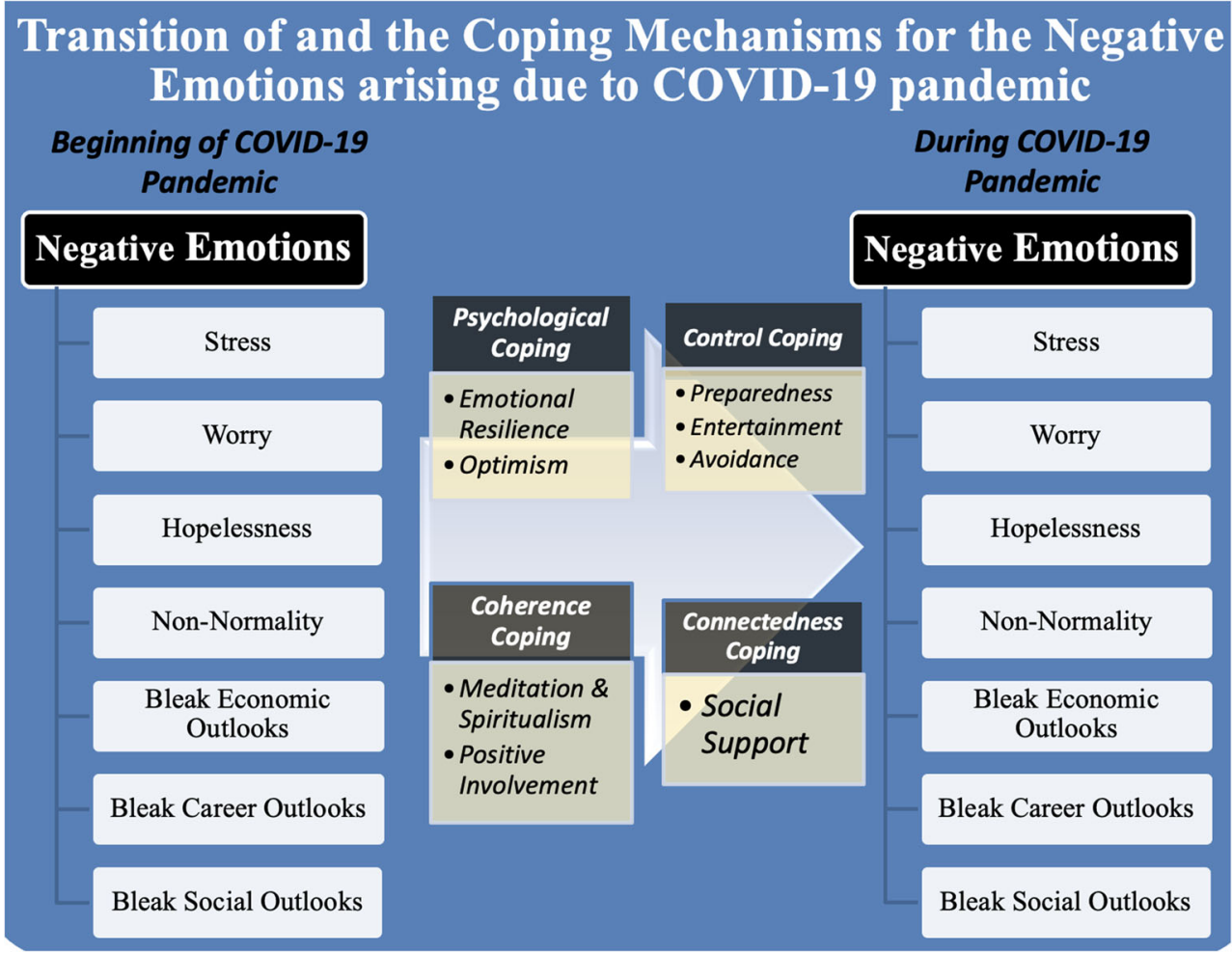

The article is divided into six sections. The 'Introduction' section introduces the topic, the 'Review of literature' section presents the review of relevant literature, the 'Database and methodology' section outlines the database and research methodology, the 'Results and findings' section is the results and findings, the 'Discussion' section highlights the discussion, and the 'Concluding remarks' section concludes the article.

\section{Review of literature}

This section of the study is further divided into two sub-sections. In the 'Psychology of negative emotions' sub-section, the studies related to the psychology of negative emotions are discussed, and in the 'Psychology of coping' sub-section, the studies related to the psychology of coping are discussed.

\section{Psychology of negative emotions}

Several stress emotions were recognized by Lazarus (1985), such as anger, hopelessness, fear, depression, guilt, fear, threat, anxiety, denial, sense of loss, and like. Lazarus (1985), in 'appraisal and reappraisal theory', has termed 'appraisal' as the process of appraising the environment and responding to the emotions. However, this method is not static. As the environment and cognitive states are evolving, 'reappraisal' is an integral part of explaining the individual's emotional states as an outcome of the environment. Constant evaluations focusing on input from the environmental and cognitive assessments result in fluctuating emotions where anger can substitute anxiety and like. The theory forms the base of our study, as an individual carries several negative emotions to varying degrees as a consequence of an everchanging stressful environment.

However, The Print (Misra 2020) reported an acute shortage of COVID-19 initiatives and personnel to resolve the mental well-being problems. Numerous authorities and analysts have responded to or suggested 'new reality' or 'normal'. This fear of their life ever returning to normal is classified as 'non-normality' in our study.

Rishi et al. (2021) focus on the psychological impacts of COVID-19 in India. The study has used both qualitative and quantitative data for the research of 261 respondents from 17 states in two phases. In the first phase, the study found that during the first 3 weeks of lockdown of the COVID-19, there were significant effects on psychology (mainly pandemic anxiety and social isolation) of the respondents. On the positive side, physical health, fitness, self-care, family connect, learning of the new skill sets, and self-growth provided new hopes to cope up, whereas negative emotions, such as fear, anxiety, frustration, and irritability for others, were the hurdles. In phase two, i.e. the sixth week of lockdown, there was an increase in negative emotions like increasing anxiety and frustration.

\section{Psychology of coping}

Lazarus (1985) accounts that 'coping' results from negative feelings to regulate certain emotions. The author 
distinguishes coping with 'direct action' and 'palliation'. Direct copying incorporates modifying the interaction with one's surroundings and taking direct actions such as planning for, preventing, or attacking the situation/ environment. Palliation, on the other hand, focuses on abating, moderating, and tolerating, i.e. 'seeking comfort' with regards to the distressing reactions arising out of negative emotions. Palliation approaches can involve detaching oneself from distressing thinking by regulated processes like yoga or meditation.

More recently, other forms of coping behaviours have been observed by researchers studying natural disasters. Reich (2006) came up with the '3Cs' model to account for 'control, coherence, and connectedness' as forms of coping. Control, to a great extent, resonates with Lazarus's (1985) 'direct action' strategies of coping. The second C-'coherence' is the 'logical' approach towards making sense of the situation. The third C-'connectedness' addresses the innate human need for social support.

Millar et al. (2021) studied the impact of the COVID-19 pandemic and lockdown restrictions in India on the psychological, social, and behavioural changes of the public. The study used cross-sectional data of 234 respondents collected after the completion of the first week of lockdown. The PLS-SEM model was used to find out the association between health anxiety, coping mechanisms, and locus of control and age. The study found that younger people have faced more health-related anxiety and they are more engaged with social media. The study also concluded that mindfulness-based strategies can also decrease health anxiety by increasing the patience level experienced during the COVID-19 pandemic.

Shamblaw et al. (2021) examined the relationship between 14 coping strategies with the symptoms of quality of life, anxiety, and depression during the COVID pandemic. Anxiety and depression were found to significantly mediate the relationship between quality of life and coping. The authors further found positive reframing to be the most effective coping strategy.

In a study concerning the impact of COVID-19 on European police officers and the coping resources to deal with the same, Frenkel et al. (2021) found that 'preparing for a pandemic requires three primary paths: (1) enacting unambiguous laws and increasing public compliance through media communication, (2) being logistically prepared, and (3) improving stress regulation skills in police training'. Y1ldırım et al. (2021) found COVID-19 coping to be a mediator of the relation between general health and COVID-19 anxiety. Kar et al. (2021) found that individuals who practiced avoidance forms of copying or were unsure regarding the coping strategies had greater depression or anxiety and stress.

\section{Database and methodology}

\section{Data collection and specification}

This study has used simple random sampling technique for data collection. The primary data was collected through Google Forms in the month of July 2020. Usable data for the study comprised 581 respondents out of 950 in Delhi. Rest of the questionnaire was incomplete. The data is highly diverse and spreads over diverse ages, income, education, and gender. The independent and dependent variables in our study are measured on a 7-point Likert scale.

The study initially selects eight independent variables that represent various coping strategies. Later, one of the variablespreparedness was split into two parts and was treated as comprising two distinct variables measuring different preparedness-proactive and preventive dimensions. The reasoning and explanation for the same are mentioned in the section ahead.

'Optimism' which is a part of psychological coping, was measured using two items, OT1, 'I am sure we will find a cure of COVID very soon', and OT2, 'I am highly optimistic that the current situation will change soon, which were developed upon taking cues from the Life Orientation Test-Revised (LOT-R) inventory (Scheier et al. 1994).

'Emotional resilience', which is another aspect of psychological coping, was measured using two items, ER1, 'In general, I think I can control my emotions well', and ER2, 'I can stay calm in tough circumstances' adopted from 'Adolescent Resilience Scale' initially developed by Atsushi et al. (2002).

'Preparedness' which is part of control coping varies from one situation to another. Cues from the Coping Inventory's task-oriented coping dimension for Stressful Situations (CISS) (Strelau et al. 2020) were taken, and two items measuring preparedness uniquely for the COVID-19 situation were developed. The items were PR1, 'I regularly take immunity boosting supplements and medicines such as Kadha or Giloy, Ashwagandha, Vitamin C, etc.', and PR2, 'I strictly adhere to preventive measures such as social distancing, wearing face masks when outside, and washing hands regularly'.

Control coping consists of 'entertainment' and 'avoidance' dimensions in our study. However, some entertainment aspects overlap avoidance because entertainment is sometimes sought to avoid a difficult situation. Cues from avoidanceoriented coping from CISS were taken, and entertainment and avoidance were segregated into two separate dimensions. Entertainment was hence measured using two items ET1, 'I have been binge-watching movies/Netflix/Amazon Prime/ YouTube etc to keep my mind off COVID', and ET2, 'I have excessively increased my social networking usage through Whatsapp/Instagram/Facebook/TikTok etc to keep my mind off COVID'. Avoidance was measured using single-item AVD: 'I have been avoiding the thoughts and news related 
to COVID'. Taking the cues from CISS, the items were developed uniquely for the study based on our observations.

As part of coherence coping, 'meditation and spiritualism' was measured using two items explicitly modified for the COVID-19 situation based on the Spiritual Transcendence Scale (STS) (Piedmont and Leach, 2002). The two items were SP1, 'I have been performing meditation techniques (prayer/ yoga/pranayama/relaxing music etc) regularly to fend off COVID related negative feelings', and SP2, 'Spiritualism has been an important factor for me to fight COVID related anxiety'.

'Positive involvement' is another aspect of coherence coping and was measured using a single-item PI, 'I have involved myself in a hobby/pursuing a passion or learning a new skill or reading books or exercising enthusiastically during the pandemic to fend off COVID related negative feelings', which was based on the idea taken from a task-based item of CISS-'Use the situation to prove my ability'.

As part of connectedness coping, 'social support' was measured using two items, SS1, 'I have received adequate emotional support from my family or friends or peers during COVID pandemic', and SS2 'My friends or family or peers have always made sure that I feel better during these tough times' adapted from Multi-Dimensional Social Support Scale (Winefield et al. 2010). Seven prominent negative emotions developing among people in general due to the current COVID-19 pandemic were observed. Currently, two scales have been published measuring negative emotions as a result of COVID-19. However, both the scales, COVID Stress Scale (CSS) by Taylor et al. (2020) and Fear of COVID-19 Scale by Ahorsu et al. (2020), measure mostly the worry and stress caused due to COVID-19. Our study measured the 'stress' and 'worry' dimensions through questions based on CSS. However, several other negative emotions among people were observed as a result of the current situation such as 'hopelessness' (regarding the future), 'non-normality' (that things would never be back to normal again), financial insecurity as measured by 'economic outlooks', career insecurity as measured by 'career outlooks', and social insecurity regarding the future as measured by 'social outlooks'. All the dimensions of negative emotions arising out of the COVID-19 situation in our study were measured using single item measuring the negative emotion at the beginning of the pandemic and the modification of the same item to measure the negative emotion currently, in the middle of the pandemic.

In the present study, 'stress' was measured using singleitem ST1, 'When COVID started spreading a few months back, how worried were you about catching the virus' measuring the stress emotion at the beginning of the pandemic, and ST2, 'How worried are you now about catching the virus' measuring the current stress emotion. Similarly, 'worry' was measured using single-item WR1: 'How often did you get worrying thoughts about the virus, when COVID started spreading' measuring the worry emotion at the beginning of the pandemic and 'How often do you get worrying thoughts about the virus now' measuring the current levels of worry.

'Hopelessness' was measured using HP1, 'When COVID started spreading, how hopeless did your future appear to you', measuring such emotion at the beginning of the pandemic, and HP2, 'How hopeless does your future appear to you now due to COVID' measuring the current emotion. We adapted these items from the Beck Hopelessness Scale (BHS; Beck et al. 1974). 'Non-normality' was measured using NR1, 'When virus started spreading, how strongly did you believe that things would never be back to normal again' for the start of period, and NR2, 'How strongly do you believe now that things would never be back to normal again' for the current period.

'Bleak economic outlooks' was measured using EC1, 'How much financially insecure did you feel regarding your future due to COVID, when it started spreading' for the start of the period, and EC2, 'Now, how much financially insecure regarding the future do you feel yourself to be due to COVID' for the current period.

'Bleak career outlooks' was measured using CR1, 'How much did you worry for your career outlooks due to COVID, when it started spreading' for the start of the period, and CR2, 'How much do you worry for your career outlooks now due to COVID' for the current period.

Finally, 'bleak social outlooks' was measured using SO1, 'When COVID started spreading, how strongly did you think that your "social life" would never be back to normal again in future' for the start of period, and $\mathrm{SO} 2$, 'How strongly do you NOW think that your 'social life' would never be back to normal again'.

\section{Methodology}

To test the various objectives, the study has applied ANOVA, GMM, and logit regression models (Tables 1, 2, and 3). Before the application of the technique, few data adjustments were made that are discussed below.

\section{Adjusting independent and dependent variables for objectivity}

As an ordinal scale has been used for measuring both dependent and independent variables, therefore, the chances of subjectivity are very high in these observations. To bring more objectivity, an adjustment for every type of variable has been used. This adjustment factor is as follows:

$Y i k=\frac{Y_{i k}}{\sum_{1}^{i} Y_{i k}} \times 10000$ 
Table 1 Legend for the estimated equation (ANOVA)

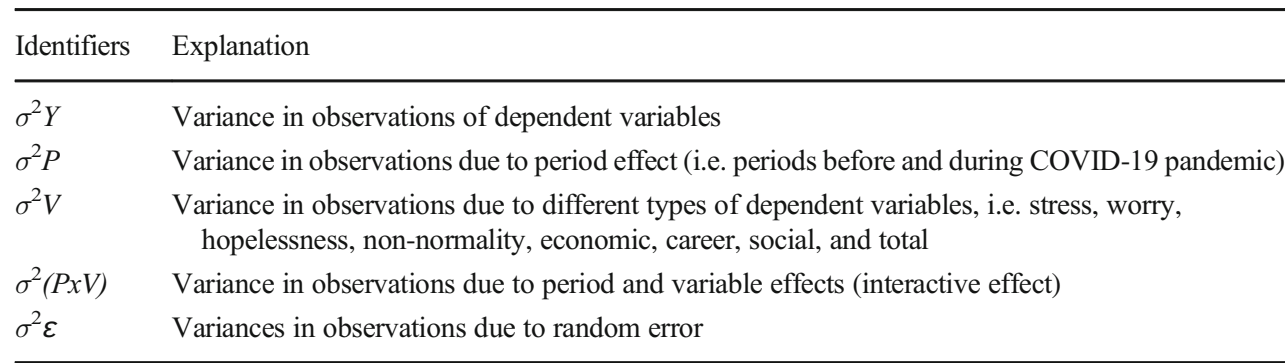

$i$ represents the observation of $\mathrm{i}^{\text {th }}$ respondent.

$k$ represents the observation of respondents in respect of the $\mathrm{k}^{\text {th }}$ variable.

In the present study, the value of $k$ is 15 since there are nine independent variables and seven independent variables, and $i$ is 1162 (i.e. $581 \times 2$ ) since there are 581 respondents; however, data for two periods was collected.

For independent variables, observations based on periods were not classified; therefore, for any given independent variable, there is the same value for any given respondent in both periods. However, for dependent variables, the observations based on periods were classified, i.e. the beginning of the COVID-19 pandemic and the current (or during the COVID-19 pandemic); therefore, any given dependent variable can be different values to any given respondent in both the periods.

'Total' as the aggregate of different dependent variables was also calculated and used as one more dependent variable.

\section{ANOVA for multiple factors}

For testing our first objective and related first hypothesis, i.e. to test whether there are changes in behaviour during the pandemic in terms of dependent variables, ANOVA has been used to test for multiple factors. ANOVA helps in testing the effect of factors on observations. Two factors in this study are present, i.e. first factor is about periods, i.e. in the beginning and during the pandemic, and the second factor pertains to different dependent variables. Through ANOVA, it can be known whether variations in observations are due to:

(1) Period effect-P (i.e. periods in the beginning and during a pandemic)

(2) Variable effect-V (i.e. different dependent variables)

(3) Interactive effect-PxV (i.e. combined impact of $\mathrm{P}$ and $\mathrm{V}$ on observations)

Model in general form Variances in Observations (i.e. dependent variables) $=$ Variances due to Period Effect + Variances due to Variable Effect + Variances due to Period and Time Effect + Error term (i.e. $\varepsilon$ )

\section{Model in the form of estimated equation}

$$
\sigma^{2} Y=\sigma^{2} P+\sigma^{2} V+\sigma^{2}(P x V)+\sigma^{2} \varepsilon
$$

In this study, we were specifically interested in whether observations are affected in two different periods, i.e. periods in the beginning and during the pandemic. We were also interested in whether observations are affected due to types of
Table 2 Legend for the estimated equation

\begin{tabular}{llll}
\hline $\begin{array}{l}\text { Identifiers } \\
\text { Dependent variables }\end{array}$ & Explanation & $\begin{array}{l}\text { Identifiers } \\
\text { Independent variables }\end{array}$ & Explanation \\
\hline STRES & Stress & $D$ & $=1$ for period during COVID-19 \\
$W R Y$ & Worry & & $=0$ for period before COVID-19 \\
$H L N$ & Hopelessness & OPT & Optimism \\
NOR & Non-normality & PRE1 & Pro preparedness \\
$E C O$ & Economic & PRE1 & Pre preparedness \\
$C R E$ & Career & ERS & Emotional resilience \\
SOC & Social & $S P M$ & Spiritualism \\
$T O T$ & Total & $P I N$ & Positive involvement \\
& & $E N T$ & Entertainment \\
& & $A V D$ & Avoidance \\
& & $S S P$ & Social support \\
\hline
\end{tabular}


Table 3 Legend for dependent variables of LOGIT regression

\begin{tabular}{ll}
\hline ESTRES & Estimated value of stress \\
EWRY & Estimated value of worry \\
$E H L N$ & Estimated value of hopelessness \\
$E N O R$ & Estimated value of non-normality \\
$E E C O$ & Estimated value of economic \\
$E C R E$ & Estimated value of career \\
ESOC & Estimated value of social \\
$E T O T$ & Estimated value of total \\
\hline
\end{tabular}

variables, i.e. stress, worry, hopelessness, non-normality, economic, career, social, and total (all the negative emotions combined). Lastly, we were also interested in interactive effect, i.e. whether observations are affected due to the combined effect of different periods and variables.

\section{T-test with unequal variances}

T-test with unequal variances was used for the second objective and related hypothesis, i.e. to test whether there are adverse behaviour changes during the pandemic in dependent variables. However, this was a one-tailed test since we were interested in adverse behaviour changes during the pandemic regarding dependent variables. Secondly, $t$-test with unequal variances was used because respondents tend to behave differently at different periods. The authors conducted a $t$-test with unequal variances using MS Excel for each of our eight dependent variables separately for 581 observations and hypothesized a mean difference of 0 .

\section{Regression through GMM}

Regression analysis for the third objective and related hypothesis was used, i.e. to examine the relationship between independent and dependent variables. However, instead of the ordinary least square (OLS) technique, the generalized method of moments (GMM) was used since the latter is based on relatively fewer assumptions and is therefore highly unbiased, efficient, and consistent OLS. This technique was earlier used by Ullah et al. (2018).

Models in general form As there are eight dependent, we have eight equations. In general form, these equations are construed as under:

Dependent variable $=\mathrm{F}$ [Independent variables $]$

Models in the form of estimated equation Our estimated equations in a deterministic form regarding the eight general equations are as follows for each dependent variable represented on LHS.

Dependent variable (i.e. STRES, WRY, HLN, NOR, ECO, CRE, SOC, TOT $)=e^{b o} \times e^{b 1(D)} \times(O P T)^{b 2} \times(D x O P T)^{b 3} \mathrm{x}$ $(P R E 1)^{b 4} \times(D x P R E 1)^{b 5} \times(P R E 2)^{b 6} \times(D x P R E 2)^{b 7} \mathrm{x}$ $(E R S)^{b 8} \times(D x E R S)^{b 9} \times(S P M)^{b 10} \times(D x S P M)^{b 11} \times(P I N)^{b 12} \mathrm{x}$ $(D x P I N)^{b 13} \times(E N T)^{b 14} \times(D x E N T)^{b 15} \times(A V D)^{b 16} \mathrm{x}$ $(D x A V D)^{b 17} \times(S S P)^{b 18} \times(D x S S P)^{b 19}$

Thereafter, to conduct regression analysis for aboveestimated equations, the natural logarithm of both sides was taken, and as a consequence after this step, the estimated equations in the deterministic form became as follows:

$\ln$ (Dependent variable) i.e. $[\ln (\mathrm{STRES}), \ln (\mathrm{WRY})$, $\ln (\mathrm{HLN}), \ln (\mathrm{NOR}), \ln (\mathrm{ECO}), \ln (\mathrm{CRE}), \ln (\mathrm{SOC}), \ln (\mathrm{TOT})]=$ $\mathrm{b}_{0}+\mathrm{b}_{1} \ln \left(\mathrm{e}^{\mathrm{D}}\right)+\mathrm{b}_{2} \ln (\mathrm{OPT})+\mathrm{b}_{3} \ln \left(\mathrm{e}^{\mathrm{D}}\right) \ln (\mathrm{OPT})+\mathrm{b}_{4} \ln (\mathrm{PRE} 1)+$ $b_{5} \ln \left(e^{D}\right) \ln (P R E 1)+b_{6} \ln (P R E 2)+b_{7} \ln \left(e^{D}\right) \ln (P R E 2)+$ $\mathrm{b}_{8} \ln (\mathrm{ERS})+\mathrm{b}_{9} \ln \left(\mathrm{e}^{\mathrm{D}}\right) \ln (\mathrm{ERS})+\mathrm{b}_{10} \ln (\mathrm{SPM})+$ $\mathrm{b}_{11} \ln \left(\mathrm{e}^{\mathrm{D}}\right) \ln (\mathrm{SPM})+\mathrm{b}_{12} \ln (\mathrm{PIN})+\mathrm{b}_{13} \ln \left(\mathrm{e}^{\mathrm{D}}\right) \ln (\mathrm{PIN})$ $+\mathrm{b}_{14} \ln (\mathrm{ENT})+\mathrm{b}_{15} \ln \left(\mathrm{e}^{\mathrm{D}}\right) \ln (\mathrm{ENT})+\mathrm{b}_{16} \ln (\mathrm{AVD})+$ $\mathrm{b}_{17} \ln \left(\mathrm{e}^{\mathrm{D}}\right) \ln (\mathrm{AVD})+\mathrm{b}_{18} \ln (\mathrm{SSP})+\mathrm{b}_{19} \ln \left(\mathrm{e}^{\mathrm{D}}\right) \ln (\mathrm{SSP})$

As this is a social science approach, to judge the significance of a parameter, a relatively liberal approach was adopted. The basis for analysing parameters obtained through regression analysis shall base on an assertion that $p$-value of $\beta^{\wedge}$ for independent variables lying in the range of $0.00-0.10$ shall classify as 'good' estimator and the $p$-value lying in the range of $0.10-0.15$ shall classify as 'moderate' estimator of the dependent variable. $p$-values greater than 0.15 have been considered insignificant.

\section{Logistic (LOGIT) regression}

LOGIT regression was used for our fourth objective and related hypothesis, i.e. to test whether controlling adverse behaviour with independent variables can bring normalcy in the behaviour. LOGIT regression can help locate the factors that will help converge in normalcy in the behaviour during the pandemic in dependent variables.

LOGIT regression estimates the behaviour differences between two dichotomous situations (Chatterjee and Chattopadhyay 2019) (i.e. dependent variables in LOGIT regression which in our study are two different periods) due to change in independent variables of LOGIT regression which in our study are estimated values of stress, worry, hopelessness, non-normality, economic, career, social, and total. Thus LOGIT regression determines the convergence from the beginning of the pandemic to the current or during the pandemic period due to change in estimated values of stress, worry, hopelessness, non-normality, economic, career, social, and total.

Model of LOGIT regression in general form Maximize the probability $(P)$ of observations falling into either 0 (period in 
the beginning of the pandemic) or 1 (period current/during a pandemic) $=\mathrm{F}$ (independent variables).

\section{Model of LOGIT regression in estimated form}

$$
P=\frac{1}{1+e^{-z}}
$$

Whereas:

$P=$ Dependent variable (in our study, if it is period during pandemic, then $P=1$, and if it is period at the beginning of the pandemic, then $P=0$ )

$$
\begin{aligned}
\mathrm{z}= & a_{0}+a_{1} \mathrm{ESTRES}+a_{2} \mathrm{EWRY}+a_{3} \mathrm{EHLN}+a_{4} \mathrm{ENOR} \\
& +a_{5} \mathrm{EECO}+a_{6} \mathrm{ECRE}+a_{7} \mathrm{ESOC}+a_{8} \mathrm{ETOT}
\end{aligned}
$$

If we further solve this equation, then we deduce to:

$$
\begin{aligned}
\ln \frac{P}{1-P}= & a_{0}+a_{1} \text { ESTRES }+a_{2} \mathrm{EWRY}+a_{3} \text { EHLN } \\
& +a_{4} \text { ENOR }+a_{5} \mathrm{EECO}+a_{6} \mathrm{ECRE}+a_{7} \mathrm{ESOC} \\
& +a_{8} \text { ETOT }
\end{aligned}
$$

In general form, change in LOGIT implies a change in $\ln \frac{P}{1-P}$ for per unit change in an independent variable of LOGIT regression.

We are particularly interested in those independent variables of LOGIT regression whose odd ratio $>1$ since these variables would cause adverse changes in behaviour during the COVID-19 pandemic, and as such, these variables need to be controlled.

Estimated values of variables instead of actual values of variables in LOGIT regression As we were interested in locating those variables causing adverse changes in behaviour during the COVID-19 pandemic but are also interested in controlling these variables to prevent adverse changes in behaviour during the pandemic, the estimated values of variables were used instead of actual values of variables in LOGIT regression.

LOGIT results contained some insignificant factors; hence through stepwise - regression, the estimated equation was further improved, and the revised estimated equation is as follows:

$$
\begin{aligned}
\ln \frac{P}{1-P}= & \mathrm{a}_{0}+\mathrm{a}_{1}(\text { EWRY }+ \text { EHLN })+\mathrm{a}_{2} \text { EECO }+\mathrm{a}_{3} \text { ECRE } \\
& +\mathrm{a}_{4} \text { ESOC }+\mathrm{a}_{5} \text { ETOT }
\end{aligned}
$$

\section{Results and findings}

Before the application of the model, tests of data reliability and validity are required.

\section{Tests of reliability and validity for independent variables}

Independent variables were measured using two items or a single item. In such a case, establishing composite reliability using the traditional approach of Cronbach's $\alpha$ is not possible. However, according to Yong and Pearce (2013), a variable with two indicators can be considered reliable when the indicators are highly correlated but relatively uncorrelated with other variables' indicators. In our study, all the log-transformed indicators fulfil this criterion where $r>0.5, N=581$, and $P<0.0005$, except for the indicators belonging to 'preparedness' $r=0.178, N=581$, and $P<0.0005$, indicating that 'preparedness' is formative where the indicators (questions) belonging to this variable measure distinct, rather than similar dimensions of preparedness. This proposition can be further established using the rotated component matrix results of factor analysis presented in Table 4.

The results of Table 4 indicate five factors, each comprising two indicators, as had been proposed, except for the variable 'preparedness' whose indicators fail to load as a factor, again indicating the formative nature of this variable. 'Positive involvement' and 'avoidance' are measured using a single item.

Based on these observations, it was proposed that each of the indicators of the variable 'preparedness' represented different psychometric properties, where PR1 could be considered as 'direct action' form of coping, and PR2 could be classified as 'palliation' form of coping as per Lazarus's (1985) theory. Hence for the analysis, both these indicators would be treated as a separate variable where 'PR1' would be called 'proactive (Pro) preparedness' and 'PR2' would be referred to as 'preventive (Pre) preparedness'.

Based on factor analysis, composite reliability using the formula $\frac{\sum \lambda^{2}}{n}$ and average value extracted (AVE) measuring convergent validity using the formula $\left(\sum \lambda\right) \frac{2}{(\Sigma \lambda)}^{2}+\left(\sum \varepsilon\right)$ were measured for each variable where $\lambda$ represents factor loadings and $\varepsilon$ which is the error variance or $1-\lambda^{2}$. These results are presented in Table 5 . Discriminant validity was measured using the Fornell-Larker criterion (Fornell and Larcker 1981), the results of which are presented in Table 6.

As the composite reliability values are greater than 0.6 and AVE being greater than 0.5 , adequacy of composite reliability and convergent validity for our variables are established. The bold values are the square root of AVE of corresponding variables. The entries in bold are compared with the values in the corresponding rows and columns. The higher bold value indicates the validity and significance as per Fornell Larcker criteria.

Table 6 shows that the Fornell-Larker criterion analysis' diagonal values representing the respective AVE values' square root are greater than their correlation with any other variable. Hence discriminant validity is established. 
Table 4 Extraction method: principal component analysis

Rotated component matrix

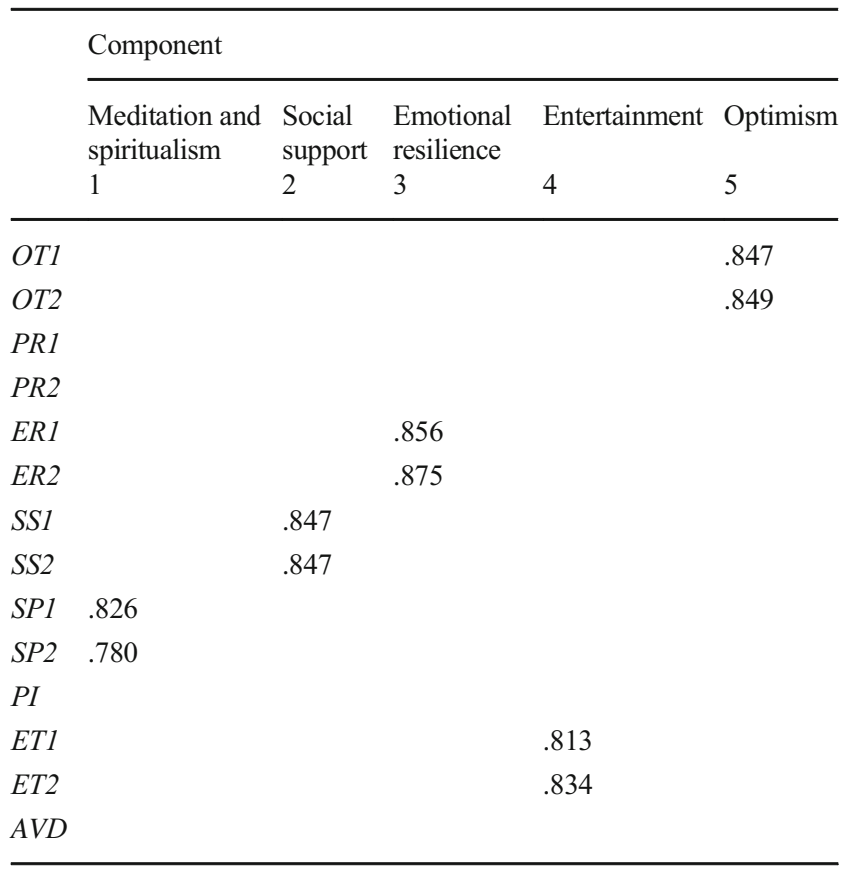

Rotation method: varimax with Kaiser normalization

\section{Tests of reliability and validity for dependent variables}

To test the dependent variable's internal consistency reliability consisting of different dimensions of negative emotions, Cronbach's $\alpha$ was used separately for two different time periods represented by the dependent variable (i.e. the beginning of pandemic and during the period). These results are presented in Table 7.

As the value of Cronbach's $\alpha$ is greater than 0.7 in both cases, it can be concluded that internal consistency reliability is established for our dependent variable (Cortina 1993).

Table 5 AVE and composite reliability

\begin{tabular}{lcc}
\hline Variable & AVE & Composite reliability \\
\hline Spiritualism & 0.645 & 0.784 \\
Optimism & 0.719 & 0.837 \\
Emotional resilience & 0.749 & 0.856 \\
Social support & 0.718 & 0.834 \\
Entertainment & 0.678 & 0.808 \\
Positive involvement & & Single item \\
Avoidance & & Single item \\
Pro preparedness & & Single item \\
Pre preparedness & & Single item \\
\hline
\end{tabular}

To test the convergent validity of different negative emotions representing a unidirectional construct, their correlation was tested. Again, this was done for both periods, i.e. the beginning of the pandemic and during the pandemic. It was observed that a significant positive correlation $(p<0.01)$ exists among all the negative emotions comprising different dimensions of the dependent variable. This proves convergent validity, but only to an extent, as the correlation among various parameters was not high enough $(>0.7)$. However, this is acceptable in this study as it was never intended to treat all the negative emotions as a single dependent variable for our analysis, rather to treat them separately to assess their relationship with independent variables. Hence, it can be concluded that different dimensions of negative emotions do possess convergent validity, but only to a moderate extent represent each factor's uniqueness, supporting the view to treat them as separate dependent variables for the analysis.

ANOVA test through SPSS was conducted, and the results of the test are as follows:

Table 8 shows that the $p$-value of $\mathrm{P}, \mathrm{V}$, and $\mathrm{P} \times \mathrm{V}$ is very significant, which implies changes in behaviour during the pandemic in dependent variables. Thus first hypothesis can be accepted that there is a behavioural effect during the pandemic in dependent variables.

The results of our t-test with unequal variances are shown in Table 9.

From the above results, it is evident that all dependent variables, except 'worry', have higher values during the pandemic than at the beginning of the pandemic, with a significant $p$-value in almost all cases. Thus, the second hypothesis cannot be rejected, i.e. there are adverse behavioural changes during the pandemic in dependent variables.

Results based on the estimated equations as proposed above derived using the GMM technique for each of the dependent variables are mentioned in Table 10.

The results of GMM regression reflect a two-fold interpretation. Firstly, a simple log of the independent variable [ln(independent variable) $]$ reflects the effectiveness of that particular variable in explaining the respective dependent variable's variance in general terms. However, $\left[\ln \left(\mathrm{e}^{\mathrm{D}}\right) \ln (\right.$ independent variable)] reflects the effectiveness of the particular variable in explaining the variance of the respective dependent variable as we approach the second period, i.e. during the COVID-19 pandemic. For example, while considering the impact of 'avoidance (AVD)' on 'stress', it can be observed that in general, avoiding the stressful situation has a positive relation with 'stress' emotion (coefficient $=0.113, p<0.05$ ); however, during COVID19 pandemic, avoiding the situation has a significantly negative relation with 'stress' emotion (coefficient $=-0.144, p<0.05$ ).

The results of the GMM regression have been summarized in Table 11. 
Table 6 Fornell-Larcker criterion analysis

Fornell-Larcker Criterion Analysis

\begin{tabular}{|c|c|c|c|c|c|c|c|c|c|}
\hline & Optimism & $\begin{array}{l}\text { Pro } \\
\text { Preparedness }\end{array}$ & $\begin{array}{l}\text { Pre } \\
\text { Preparedness }\end{array}$ & $\begin{array}{l}\text { Emotional } \\
\text { Resilience }\end{array}$ & Spiritualism & $\begin{array}{l}\text { Positive } \\
\text { Involvement }\end{array}$ & Entertainment & Avoidance & $\begin{array}{l}\text { Social } \\
\text { Support }\end{array}$ \\
\hline Optimism & 0.712 & & & & & & & & \\
\hline $\begin{array}{l}\text { Pro } \\
\quad \text { Preparedness }\end{array}$ & 0.306 & $\begin{array}{l}\text { Formative } \\
\text { Measure }\end{array}$ & & & & & & & \\
\hline $\begin{array}{l}\text { Pre } \\
\quad \text { Preparedness }\end{array}$ & 0.204 & 0.178 & $\begin{array}{l}\text { Formative } \\
\text { Measure }\end{array}$ & & & & & & \\
\hline $\begin{array}{l}\text { Emotional } \\
\text { Resilience }\end{array}$ & 0.331 & 0.166 & 0.171 & 0.749 & & & & & \\
\hline Spiritualism & 0.336 & 0.383 & 0.133 & 0.28 & 0.645 & & & & \\
\hline $\begin{array}{l}\text { Positive } \\
\text { Involvement }\end{array}$ & 0.224 & 0.253 & 0.198 & 0.226 & 0.357 & $\begin{array}{l}\text { Single-Item } \\
\text { Construct }\end{array}$ & & & \\
\hline Entertainment & 0.007 & 0.056 & 0.073 & -0.035 & 0.015 & 0.159 & 0.678 & & \\
\hline Avoidance & 0.034 & 0.074 & 0.024 & 0.004 & 0.134 & 0.144 & 0.272 & $\begin{array}{l}\text { Single-Item } \\
\text { Construct }\end{array}$ & \\
\hline Social Support & 0.276 & 0.262 & 0.284 & 0.375 & 0.24 & 0.228 & 0.029 & .070 & 0.718 \\
\hline
\end{tabular}

LOGIT regression was conducted for the estimated equation with the help of EViews, and results for the same are shown in Table 12.

In the above results, there is high $R$ and $R^{2}$; thus, this model is very explanatory. Secondly, the constant is highly insignificant since the $p$-value of the constant is 0.4654 , and all factors turn out to be significant, implying that there is no overspecification and no under-specification in the estimated model of LOGIT regression (Table 13).

\section{Summary of LOGIT results}

The estimated value of 'career' turns out to be the most substantial factor for converging behaviour in dependent variables to normality during the pandemic.

The estimated value of 'total' also became another decisive factor for converging behaviour in dependent variables to normalcy during a pandemic.

Estimated values of worry, hopelessness, social, and economic outlooks have high $p$-values, but they are not relevant in our study since their odd ratio is less than 1 .

Based on overall analysis, the fourth hypothesis can be accepted, i.e. control of adverse behaviour during the pandemic with independent variables can bring normalcy in the behaviour.

Table 7 Internal consistency reliability (Cronbach's $\alpha$ )

\begin{tabular}{ll}
\hline Beginning of pandemic & 0.828 \\
During pandemic & 0.833
\end{tabular}

\section{Discussion}

The research is incomparable in certain respects. Even though theoretical studies have been conducted in the past, reflecting possible coping strategies that may effectively alleviate the negative emotions (Lazarus 1985), which negative emotions do coping mechanisms tend to relieve have never been investigated quantitatively. Biswas (2011) conducted a study exploring various coping strategies post-26/11 terror attacks in India, where the author found a wide spectrum of strategies such as detachment and wishful things, produced out of terror perception. This is one of the first studies to recognize a broad spectrum of possible coping strategies and a wide range of negative emotions during pandemic times. The interaction among various coping strategies and negative emotions was studied independently and together. Furthermore, another remarkable feature that makes this research stand out is that we examined the connection between coping strategies and negative emotions in general terms and precisely as we reach the pandemic period deeper.

The $t$-test results revealed that negative emotions increased upon further dive in the pandemic phase. This finding attributes that limited solution or robust treatment for COVID-19 symptoms has been discovered in the world. This has created mass hysteria and panic among the population with little reason to subside until promising cure findings. However, one of the negative emotions, 'worry', i.e. worrying thoughts, was observed not to be significantly elevated over this period. Perhaps the answer lies in the 'avoidance model of worry' (AMW), which theorizes that 'Worry is reinforced as a coping strategy because most worries never actually occur, leaving the worrier with a feeling of having controlled the feared situation successfully, without the unpleasant sensations associated with exposure' (Behar et al. 2009). However, this does 
Table 8 ANOVA test for observations in respect of dependent variables

\begin{tabular}{|c|c|c|c|c|c|}
\hline Source & Type III sum of squares & $D f$ & Mean square & $F$ & $\begin{array}{l}p- \\
\text { value }\end{array}$ \\
\hline Corrected model & 2717188.741 & 15 & 181145.916 & 3429.188 & 0.0000 \\
\hline Intercept & 2108433.735 & 1 & 2108433.735 & 39913.768 & 0.0000 \\
\hline$P$ & 2689.910 & 1 & 2689.910 & 50.921 & 0.0000 \\
\hline$V$ & 2710843.373 & 7 & 387263.339 & 7331.100 & 0.0000 \\
\hline$P x V$ & 3655.458 & 7 & 522.208 & 9.886 & 0.0000 \\
\hline Error & 490213.429 & 9280 & 52.825 & & \\
\hline Total & 5315835.905 & 9296 & & & \\
\hline Corrected total & 3207402.170 & 9295 & & & \\
\hline \multicolumn{6}{|c|}{$R^{2}=0.847$ (adjusted $R^{2}=0.847$ ) } \\
\hline
\end{tabular}

not mean that worry reduces over time; it implies that worry does not increase overtime, as suggested by our findings.

Some critical observations could be derived from the GMM regression result summary as provided in Table 10. In terms of the significance of coping strategies in general terms when handling negative emotions, entertainment was found to have a strong positive relationship with all the negative emotions considered in our research. This indicates that entertainment usually results in negative emotions rather than elimination. Our research finds out that entertainment media minimize stress when used as a means of immediate dissociation from the stressful condition or when breaking it (Prestin and Nabi 2020); however, if entertainment media is used to prevent the stressful situation and to recover from it, it overwhelms our senses and itself starts behaving as stressors rather than stress reliever (Davenport 2015). As can be observed, entertainment was used as an 'escaping strategy' rather than a 'relieving strategy'; hence, it led to further negative emotions in general and COVID-19 times.

Table 9 T-test with unequal variances

T-test with unequal variances

\begin{tabular}{|c|c|c|c|c|c|}
\hline Stress & Beginning of Pandemic & During Pandemic & Worry & Beginning of Pandemic & During Pandemic \\
\hline Mean & 8.409 & 8.802 & Mean & 8.578 & 8.634 \\
\hline Variance & 9.391 & 7.812 & Variance & 9.263 & 9.315 \\
\hline$D f$ & 1150 & & $D f$ & 1160.000 & \\
\hline t Stat & -2.284 & & t Stat & -0.311 & \\
\hline$P(T<=$ t) one-tail & 0.011 & & $P(T<=t)$ one-tail & 0.378 & \\
\hline Hopelessness & Beginning of Pandemic & During Pandemic & Normality & Beginning of Pandemic & During Pandemic \\
\hline Mean & 8.394 & 8.818 & Mean & 8.163 & 9.049 \\
\hline Variance & 15.785 & 16.291 & Variance & 17.685 & 17.904 \\
\hline$D f$ & 1160.000 & & $d f$ & 1160.000 & \\
\hline$t$ Stat & -1.807 & & $t$ Stat & -3.580 & \\
\hline$P(T<=$ t) one-tail & 0.035 & & $P(T<=t)$ one-tail & 0.000 & \\
\hline Economic & Beginning of Pandemic & During Pandemic & Career & Beginning of Pandemic & During Pandemic \\
\hline Mean & 8.262 & 8.950 & Mean & 8.117 & 9.095 \\
\hline Variance & 13.975 & 14.659 & Variance & 14.079 & 14.721 \\
\hline$D f$ & 1159.000 & & $d f$ & 1159.000 & \\
\hline$t$ Stat & -3.100 & & $t$ Stat & -4.392 & \\
\hline$P(T<=$ t) one-tail & 0.001 & & $P(T<=t)$ one-tail & 0.000 & \\
\hline Social & Beginning of Pandemic & During Pandemic & Total & Beginning of Pandemic & During Pandemic \\
\hline Mean & 8.167 & 9.045 & Mean & 58.089 & 62.393 \\
\hline Variance & 14.544 & 14.040 & Variance & 326.420 & 329.312 \\
\hline$D f$ & 1160.000 & & $d f$ & 1160.000 & \\
\hline$t$ Stat & -3.958 & & $t$ Stat & -4.051 & \\
\hline$P(T<=$ t) one-tail & 0.000 & & $P(T<=t)$ one-tail & 0.000 & \\
\hline
\end{tabular}


Table 10 GMM regression result summary

\begin{tabular}{|c|c|c|c|c|c|c|c|c|c|c|c|c|}
\hline \multirow[b]{2}{*}{ Variable } & \multicolumn{3}{|c|}{$\ln$ (Stress) } & \multicolumn{3}{|c|}{$\ln$ (Worry) } & \multicolumn{3}{|c|}{$\ln$ (Hopelessness) } & \multicolumn{3}{|c|}{$\ln$ (Normality) } \\
\hline & Coefficient & $\begin{array}{l}\text { Std. } \\
\text { error }\end{array}$ & $\mathrm{p}$ value & Coefficient & $\begin{array}{l}\text { Std. } \\
\quad \text { error }\end{array}$ & $p$ value & Coefficient & $\begin{array}{l}\text { Std. } \\
\text { error }\end{array}$ & $p$ value & Coefficient & $\begin{array}{l}\text { Std. } \\
\quad \text { error }\end{array}$ & $p$ value \\
\hline Constant & 1.046 & 0.299 & 0.001 & 1.053 & 0.249 & 0.000 & 2.176 & 0.296 & 0.000 & 2.306 & 0.309 & 0.000 \\
\hline $\ln \left(e^{D}\right)$ & 0.234 & 0.425 & 0.582 & 0.155 & 0.383 & 0.686 & 0.374 & 0.425 & 0.379 & 0.488 & 0.400 & 0.224 \\
\hline $\ln (O P T)$ & 0.081 & 0.092 & 0.383 & 0.188 & 0.077 & 0.315 & -0.143 & 0.101 & 0.157 & $-0.278 * *$ & $0.097 * *$ & $0.004 * *$ \\
\hline $\ln \left(e^{D}\right) \ln (O P T)$ & -0.006 & 0.114 & 0.955 & -0.097 & 0.102 & 0.342 & -0.058 & 0.146 & 0.691 & -0.136 & 0.139 & 0.328 \\
\hline $\ln (P R E 1)$ & 0.036 & 0.073 & 0.622 & 0.111 & 0.086 & 0.197 & -0.062 & 0.084 & 0.464 & $-0.199 *$ & $0.130 *$ & $0.126^{*}$ \\
\hline $\ln \left(e^{D}\right) \ln (P R E 1)$ & $0.179 *$ & $0.122 *$ & $0.144^{*}$ & 0.157 & 0.131 & 0.229 & 0.177 & 0.123 & 0.151 & 0.232 & 0.161 & 0.151 \\
\hline $\ln (P R E 2)$ & 0.055 & 0.042 & 0.195 & $0.138 * *$ & $0.042 * *$ & $0.001 * *$ & 0.044 & 0.054 & 0.413 & 0.033 & 0.053 & 0.533 \\
\hline $\ln \left(e^{D}\right) \ln (P R E 2)$ & 0.007 & 0.057 & 0.902 & -0.064 & 0.057 & 0.264 & 0.061 & 0.075 & 0.412 & -0.006 & 0.075 & 0.933 \\
\hline $\ln (E R S)$ & 0.000 & 0.091 & 0.999 & -0.057 & 0.065 & 0.382 & $-0.156^{* *}$ & $0.079 * *$ & $0.050 * *$ & 0.007 & 0.090 & 0.934 \\
\hline $\ln \left(e^{D}\right) \ln (E R S)$ & -0.126 & 0.115 & 0.272 & -0.082 & 0.090 & 0.361 & -0.006 & 0.119 & 0.958 & -0.068 & 0.136 & 0.616 \\
\hline $\ln (S P M)$ & 0.018 & 0.049 & 0.719 & -0.035 & 0.054 & 0.514 & 0.091 & 0.064 & 0.154 & 0.045 & 0.068 & 0.505 \\
\hline $\ln \left(e^{D}\right) \ln (S P M)$ & -0.028 & 0.069 & 0.682 & 0.066 & 0.071 & 0.358 & -0.074 & 0.089 & 0.403 & -0.056 & 0.093 & 0.546 \\
\hline $\ln (P I N)$ & 0.086 & 0.062 & 0.168 & 0.082 & 0.070 & 0.240 & -0.054 & 0.078 & 0.484 & 0.088 & 0.070 & 0.210 \\
\hline $\ln \left(e^{D}\right) \ln (P I N)$ & -0.044 & 0.083 & 0.597 & 0.004 & 0.090 & 0.968 & -0.033 & 0.101 & 0.743 & -0.074 & 0.095 & 0.434 \\
\hline $\ln (E N T)$ & $0.098^{* *}$ & $0.058 * *$ & $0.093 * *$ & $0.117 * *$ & $0.047^{* *}$ & $0.013^{* *}$ & $0.249^{* *}$ & $0.060 * *$ & $0.000^{* *}$ & $0.115^{* *}$ & $0.060 * *$ & $0.056^{* *}$ \\
\hline $\ln \left(e^{D}\right) \ln (E N T)$ & 0.050 & 0.079 & 0.530 & 0.011 & 0.070 & 0.872 & 0.061 & 0.086 & 0.480 & $0.124 *$ & $0.081^{*}$ & $0.124 *$ \\
\hline $\ln (A V D)$ & $0.113^{* * *}$ & $0.043 * *$ & $0.009 * *$ & 0.046 & 0.038 & 0.221 & $0.103^{* *} *$ & $0.050^{* *} *$ & $0.041^{* *}$ & 0.058 & 0.047 & 0.219 \\
\hline $\ln \left(e^{D}\right) \ln (A V D)$ & $-0.144^{* *}$ & $0.054 * *$ & $0.008 * *$ & $-0.085^{* *}$ & $0.052 * *$ & $0.100^{* *}$ & -0.068 & 0.072 & 0.351 & -0.003 & 0.069 & 0.963 \\
\hline $\ln (S S P)$ & 0.025 & 0.075 & 0.737 & -0.079 & 0.083 & 0.341 & -0.119 & 0.102 & 0.240 & -0.019 & 0.108 & 0.860 \\
\hline $\ln \left(e^{D}\right) \ln (S S P)$ & 0.016 & 0.108 & 0.884 & 0.020 & 0.114 & 0.860 & -0.216 & 0.152 & 0.155 & -0.182 & 0.150 & 0.224 \\
\hline$R$ & 0.221 & & & 0.214 & & & 0.258 & & & 0.240 & & \\
\hline$R$-squared & 0.049 & & & 0.046 & & & 0.066 & & & 0.058 & & \\
\hline Adjusted R-squared & 0.033 & & & 0.030 & & & 0.051 & & & 0.042 & & \\
\hline $\begin{array}{l}\text { Standard error of } \\
\text { regression }\end{array}$ & 0.458 & & & 0.464 & & & 0.593 & & & 0.599 & & \\
\hline \multirow[t]{2}{*}{ Prob (J-statistic) } & 0 & & & 0 & & & 0 & & & 0 & & \\
\hline & \multicolumn{3}{|c|}{$\ln ($ Economic $)$} & \multicolumn{3}{|c|}{$\ln$ (Career) } & \multicolumn{3}{|c|}{$\ln$ (Social) } & \multicolumn{2}{|c|}{$\ln$ (Total) } & \\
\hline Variable & Coefficient & $\begin{array}{l}\text { Std. } \\
\quad \text { error }\end{array}$ & $\mathrm{p}$ value & Coefficient & $\begin{array}{l}\text { Std. } \\
\text { error }\end{array}$ & $p$ value & Coefficient & $\begin{array}{l}\text { Std. } \\
\text { error }\end{array}$ & $p$ value & Coefficient & $\begin{array}{l}\text { Std. } \\
\quad \text { error }\end{array}$ & $p$ value \\
\hline Constant & 1.968 & 0.270 & 0.000 & 1.326 & 0.366 & 0.000 & 1.507 & 0.339 & 0.000 & 3.748 & 0.157 & 0.000 \\
\hline $\ln \left(e^{D}\right)$ & 0.233 & 0.372 & 0.532 & 0.566 & 0.540 & 0.295 & 0.714 & 0.507 & 0.159 & 0.227 & 0.225 & 0.314 \\
\hline $\ln (O P T)$ & -0.073 & 0.080 & 0.364 & 0.011 & 0.095 & 0.912 & $-0.233 * *$ & $0.082 * *$ & $0.005^{* *}$ & -0.068 & 0.053 & 0.201 \\
\hline $\ln \left(e^{D}\right) \ln (O P T)$ & -0.025 & 0.107 & 0.815 & -0.065 & 0.129 & 0.614 & -0.067 & 0.111 & 0.547 & -0.028 & 0.072 & 0.699 \\
\hline $\ln (P R E 1)$ & $-0.177 *$ & $0.117 *$ & $0.131^{*}$ & -0.023 & 0.121 & 0.852 & -0.009 & 0.119 & 0.938 & -0.044 & 0.058 & 0.445 \\
\hline $\ln \left(e^{D}\right) \ln (P R E 1)$ & $0.326^{* *}$ & $0.151^{* *}$ & $0.031^{* *}$ & 0.138 & 0.147 & 0.348 & 0.100 & 0.145 & 0.491 & $0.172^{* *}$ & $0.076 * *$ & $0.023 * *$ \\
\hline $\ln (P R E 2)$ & 0.067 & 0.052 & 0.197 & $0.124 * *$ & $0.053^{* *}$ & $0.019^{* *}$ & 0.067 & 0.051 & 0.190 & $0.066^{* *}$ & $0.030 * *$ & $0.026^{* *}$ \\
\hline $\ln \left(e^{D}\right) \ln (P R E 2)$ & -0.031 & 0.070 & 0.663 & -0.017 & 0.074 & 0.814 & 0.010 & 0.069 & 0.885 & 0.002 & 0.041 & 0.960 \\
\hline $\ln (E R S)$ & 0.119 & 0.084 & 0.157 & 0.026 & 0.092 & 0.778 & 0.032 & 0.074 & 0.666 & 0.001 & 0.049 & 0.983 \\
\hline $\ln \left(e^{D}\right) \ln (E R S)$ & -0.148 & 0.111 & 0.186 & $-0.214 * *$ & $0.114^{* *}$ & $0.062^{* *}$ & -0.122 & 0.108 & 0.259 & -0.065 & 0.065 & 0.320 \\
\hline $\ln (S P M)$ & 0.021 & 0.053 & 0.688 & 0.036 & 0.061 & 0.562 & $0.163 * *$ & $0.061 * *$ & $0.007 * *$ & 0.016 & 0.037 & 0.673 \\
\hline $\ln \left(e^{D}\right) \ln (S P M)$ & 0.010 & 0.077 & 0.894 & -0.014 & 0.085 & 0.870 & $-0.150 * *$ & $0.086^{* *}$ & $0.080^{* *}$ & -0.018 & 0.051 & 0.718 \\
\hline $\ln (P I N)$ & -0.034 & 0.061 & 0.581 & -0.041 & 0.076 & 0.591 & -0.056 & 0.073 & 0.448 & 0.040 & 0.043 & 0.355 \\
\hline $\ln \left(e^{D}\right) \ln (P I N)$ & -0.071 & 0.081 & 0.383 & 0.014 & 0.098 & 0.885 & 0.004 & 0.096 & 0.963 & -0.040 & 0.055 & 0.468 \\
\hline $\ln (E N T)$ & $0.210 * *$ & $0.057^{* * *}$ & $0.000 * *$ & $0.300 * *$ & $0.059 * *$ & $0.000 * *$ & $0.263^{* *}$ & $0.061 * *$ & $0.000^{* *}$ & $0.133 * *$ & $0.039 * *$ & $0.001 * *$ \\
\hline $\ln \left(e^{D}\right) \ln (E N T)$ & 0.064 & 0.078 & 0.418 & 0.092 & 0.083 & 0.270 & 0.087 & 0.086 & 0.311 & $0.085^{*}$ & $0.055^{*}$ & $0.121 *$ \\
\hline $\ln (A V D)$ & $0.105^{* *}$ & $0.052 * *$ & $0.041 * *$ & 0.070 & 0.056 & 0.208 & 0.049 & 0.047 & 0.300 & $0.070^{* *}$ & $0.031 * *$ & $0.021 * *$ \\
\hline $\ln \left(e^{D}\right) \ln (A V D)$ & $-0.114^{* *}$ & $0.069 * *$ & $0.100 * *$ & -0.074 & 0.072 & 0.310 & $-0.121 * *$ & $0.065^{* *} *$ & $0.061^{* *}$ & $-0.082 * *$ & $0.042 * *$ & $0.050 * *$ \\
\hline $\ln (S S P)$ & $-0.201 * *$ & $0.107 * *$ & $0.059 * *$ & -0.160 & 0.123 & 0.193 & -0.033 & 0.097 & 0.735 & -0.068 & 0.061 & 0.269 \\
\hline $\ln \left(e^{D}\right) \ln (S S P)$ & -0.081 & 0.150 & 0.589 & -0.070 & 0.155 & 0.651 & -0.021 & 0.144 & 0.886 & -0.096 & 0.087 & 0.270 \\
\hline$R$ & 0.247 & & & 0.289 & & & 0.291 & & & 0.315 & & \\
\hline$R$-squared & 0.061 & & & 0.084 & & & 0.084 & & & 0.099 & & \\
\hline Adjusted R-squared & 0.046 & & & 0.068 & & & 0.069 & & & 0.084 & & \\
\hline $\begin{array}{l}\text { Standard error of } \\
\text { regression }\end{array}$ & 0.559 & & & 0.589 & & & 0.557 & & & 0.347 & & \\
\hline Prob (J-statistic) & 0 & & & 0 & & & 0 & & & 0 & & \\
\hline
\end{tabular}

$p<0.10(* *), p<0.15(*)$

The most critical element in minimizing negative emotions was 'avoidance' as a coping mechanism during the pandemic. This result is consistent with the '3Cs' model of Reich (2006), where avoidance as a 'control' approach supports coping mechanisms. However, in contrast, avoidance is a significant factor that is positively associated with negative emotions in 
Table 11 Effectiveness of coping techniques in managing negative emotions in general and specifically during COVID-19 pandemic. Variables in brackets represent negative relation of the particular variable with the corresponding negative variable

\begin{tabular}{lll}
\hline Negative emotions & $\begin{array}{l}\text { Significant relationship of coping strategies } \\
\text { with negative emotions in general }\end{array}$ & $\begin{array}{l}\text { Significant relationship of coping strategies } \\
\text { with negative emotions during pandemic }\end{array}$ \\
\hline Stress & Entertainment, avoidance & Proactive preparedness, (avoidance) \\
Worry & Preventive preparedness, entertainment & (Avoidance) \\
Hopelessness & Entertainment, avoidance & (Emotional resilience) \\
Non-normality & (Optimism), (proactive preparedness), entertainment & $\begin{array}{l}\text { Entertainment } \\
\text { Economic (-ve) }\end{array}$ \\
Career (-ve) & Proactive preparedness), entertainment, avoidance, (social support) & Proactive preparedness, (avoidance) \\
Social (-ve) & (Optimism), spiritualism, entertainment & (Emotional resilience) \\
Total & Preventive preparedness, entertainment, avoidance & (Spiritualism), (avoidance) \\
\hline
\end{tabular}

general. This variation's interpretation parallels the Hofer et al. (1974) results where it was observed that the parents who denied their child's death from leukaemia displayed higher levels of stress when their child died. This suggests that while denial and avoidance can play a role as a short-term coping mechanism, it will usually prove counterproductive in the long run.

Proactive preparedness measures are positively associated with negative emotions during the pandemic; however, they were negatively associated with them in general. When we make substantial personal attempts to execute those measures, they give us a sense of control over the situation, which will be a defining factor in minimizing negative emotions in general if those positive measures were to succeed. However, despite all such efforts, the pandemic condition stays constant, and specific measures are reduced in our minds as burdens and reminders of the current pandemic that we cannot control, no matter how much proactive efforts we put in. We think this is why proactive preparedness turned out to be a significant factor leading to the COVID-19 pandemic, rather than reducing negative emotions.
Preventive preparedness interventions were positively associated with several negative emotions in general, such as worry, a feeling of negative career outlooks, and negative emotions as a whole. In general, preventative measures are only the rules that we must obey or are compelled to follow due to legal or social compulsion. These interventions are not the 'extra or proactive' initiatives to change or help us feel better. In reality, following rules can appear as hassle over time, creating negative emotions.

Optimism and social support were effective coping mechanisms in general that were inversely associated with the negative emotions of non-normality and grim social and economic outlooks. These results are in line with other studies such as those by Polizzi et al. (2020) and Fredrickson et al. (2003). During COVID-19, spiritualism was found to be a significant coping mechanism to reduce negative future social outlooks. Several other studies have also established that spiritualism can help cope with fear, anxiety, and trauma (Mathijsen 2012). According to Lazarus (1985), palliative coping strategies such as meditation and yoga can also be very effective in dealing with the debilitating
Table 12 LOGIT regression (after step-wise regression)

\begin{tabular}{llllll}
\hline Variable & Coefficient (b) & $\mathrm{e}^{\mathrm{b}}$ & Std. error & z-statistic & $\begin{array}{l}p \text { - } \\
\text { value }\end{array}$ \\
\hline CONSTANT & -1.10753 & 0.330373 & 1.517108 & -0.73003 & 0.4654 \\
EWRY + EHLN & -4.03512 & 0.017684 & 0.243941 & -16.54136 & 0.0000 \\
EECO & -1.43784 & 0.237439 & 0.202828 & -7.088977 & 0.0000 \\
ECRE & 3.593317 & 36.35446 & 0.322186 & 11.15294 & 0.0000 \\
ESOC & -0.81486 & 0.442704 & 0.162943 & -5.000844 & 0.0000 \\
ETOT & 0.94848 & 2.581782 & 0.078886 & 12.02337 & 0.0000 \\
$R$ & 0.722111 & & & & \\
McFadden R-squared & 0.521444 & & & & \\
Standard error of regression & 0.305587 & & & & \\
Prob (LR-statistic) & 0.0000 & & & & \\
\end{tabular}


Table 13 Ranking of factors along with odd ratio

\begin{tabular}{lll}
\hline Rank & Factor & Odd ratio \\
\hline 01 & ECRE & 36.35446 \\
02 & ETOT & 2.130124 \\
03 & ESOC & 0.442704 \\
04 & EECO & 0.237439 \\
05 & EWRY + EHLN & 0.017684 \\
\hline
\end{tabular}

stress when one has no choice to deal with the condition by tasking direct action towards it.

One surprising finding of our study was that spiritualism was linked to the emotion of grim perceived social outlooks in general. From the basic understanding, it is observed that an ardent spiritualist would not proactively pursue social companionship since the foundation of spiritualism is going 'inward' rather than 'outward'. However, there is a dearth of research to support such observations.

Finally, 'emotional resilience' was negatively associated/ adversely correlated with the pandemic's negative emotions such as hopelessness and negative future career outlooks. Emotional resilience is an effective psychological coping strategy inherently present in the human mind to deal with life's ups and downs. The importance of emotional reliance was highlighted in the literature (Polizzi et al. 2020).

Based on these interpretations, Fig. 2 and 3 explain the significance of prominent coping mechanisms to curb negative emotions. Table 10 and Fig. 2 and 3 represent the frequency of coping strategies towards negative emotions in aggregate. Variables denoted by the bars coloured in green reflect the positive association of the particular independent variable with the negative emotions. The variables denoted by the bars coloured in blue reflect the negative association of the particular independent variable with the negative emotions, meaning that the particular coping mechanism helps in curbing the negative emotions. It is clear from the figure that the scenario has been changed during COVID-19 period. The effect of variable 'avoidance' had changed from positive in general to negative during pandemic period. 'Proactive preparedness' has also changed its effect from positive in general to negative during the pandemic.

Through these observations, it can be inferred that during the COVID-19 pandemic, ignoring the 'firehouse of propaganda' (Paul and Matthews 2017) using news or conversations, one can avoid the 'illusory truth effect' (Hasher et al. 1977), and this proves to be the most effective coping strategy. However, this strategy will work only temporarily since it has been proven to cause negative emotions rather than curb them over time. Emotional resilience was also a useful tool to address the negative emotions during the pandemic (Khafi et al. 2014; Morgan and Southwick 2014). Some strategies are known to strengthen emotional resilience, such as learning to respond positively, being mindful and viewing situations from an open mind, and accepting and non-judgemental manner, reflecting on the present moment, embracing, rather than running away from adversity, exercising the mind by performing enduring tasks and challenging ourselves. Albert Einstein suggested that 'One should not pursue goals that are easily achieved. One must develop an instinct for what one can just barely achieve through one's greatest efforts' (Swaminathan 2013).

Finally, spiritualism was also found to be a significant factor while countering negative emotions during the pandemic. Throughout the years, the benefits of regular meditation, pranayama, yoga, etc. have been well known in Indian culture (Nagraj 2012). Optimism and social support were significant factors in general to reduce negative emotions (Jain et al. 2019). However, these were not considered relevant during COVID-19 times. These findings reflect that optimism and social support act differently in general and in an adverse situation. We believe that while optimism can usually reduce negative feelings (Dougall et al. 2001), any reinforcement factor might be needed to promote optimism. Unless we see the feeling of optimism get materialized into the reality that we have not

Fig. 2 Frequency of emotions

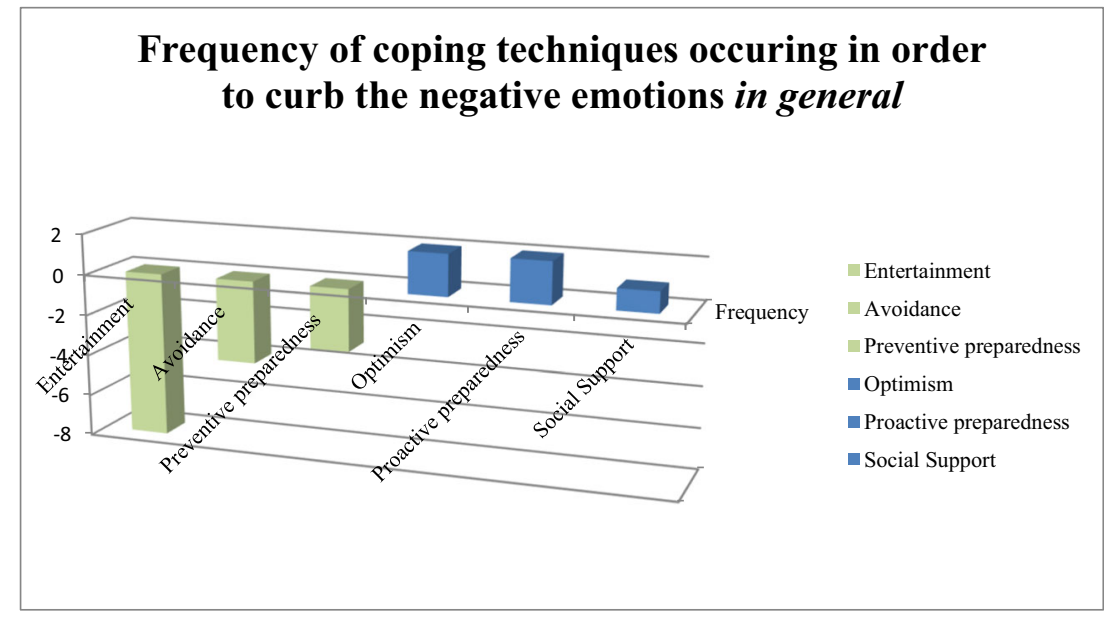


Fig. 3 Frequency of emotions

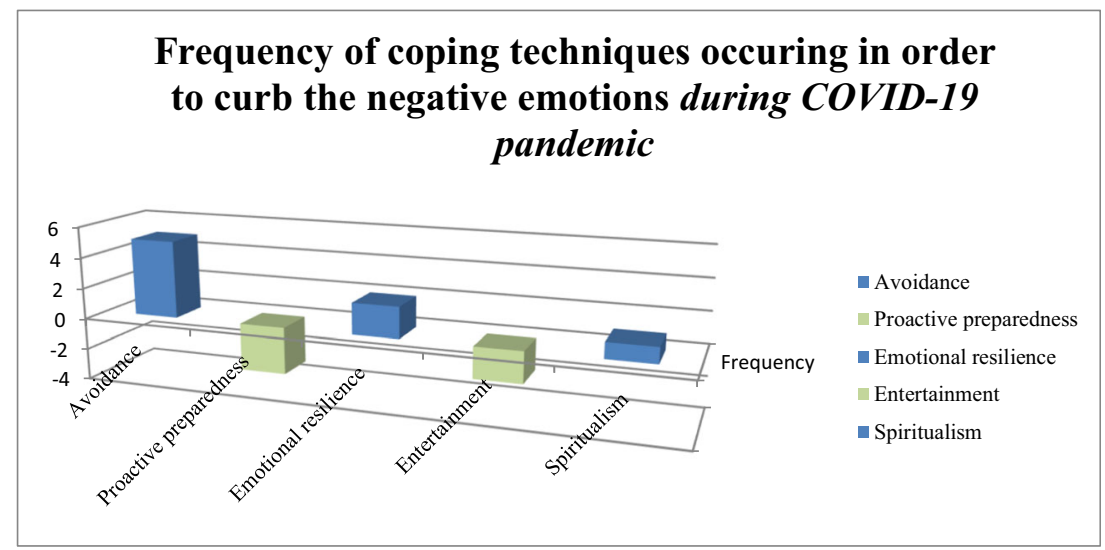

seen during COVID-19 times, it might not significantly reduce the negative emotions (Doğan et al. 2020). In general, social support is an outstanding tool for coping (Holahan et al. 1997). However, in our research, the negative emotions during the pandemic were not substantially reduced. We theorize that we would choose an escape strategy during the pandemic, as is in the 'fight or flight' response, where one might choose flight if fighting (or seeking support) does not seem to improve the situation. Our findings confirm this hypothesis that the most important coping mechanism was 'avoidance'.

LOGIT regression results suggested that the feelings of poor job outlooks and negative emotions were the strongest reasons for converging the negative emotions to normalcy during pandemic (Sharma et al. 2020; Sharma and Mahendru 2020). These findings offer further insight into how negative emotions can be regulated during a pandemic. To pacify negative emotions for bringing them to normality; the best approach will be to control the negative feelings regarding career insecurity and control the negative emotions as a whole. Using regression analysis, we established 'emotional resilience' during a pandemic and 'social support' to be the most effective measure to regulate negative career outlook feelings, whereas 'entertainment' in general is positively associated with negative career outlook feelings. Finally, through regression analysis, we observed that 'avoidance' during the pandemic was the most effective method to manage aggregate negative emotions. In contrast, proactive 'preparedness' approaches and 'entertainment' during pandemic, preventive 'preparedness' approaches, 'avoidance', and 'entertainment' are generally positively associated with the aggregate negative emotions in aggregate.

The pandemic crisis remains far from over, and no permanent remedy to the epidemic seems to be in reach (OECD Policy Responses to Coronavirus (COVID-19), 2020). New COVID cases have not recovered yet, which has profoundly impacted our economy and social structure. Further research will be required to determine the efficacy of various group coping strategies at different pandemic intervals.

\section{Concluding remarks}

COVID-19 pandemic severely impacted the well-being of individuals in financial, physical, and psychological terms. The present study aimed to observe the negative emotional states during the COVID-19 pandemic, and how such emotions change with time during the pandemic, the kind of coping mechanisms people adopt to deal with negative emotions, and which of these coping strategies prove to be most successful in alleviating the negative emotions. The study was based on model given by Reich (2006) which is based on ' $3 \mathrm{Cs}$ ' and 'direct intervention and palliation strategy'. The model helped us determine the factors that can control negative emotions during the COVID-19 pandemic in an effective manner. An extant review of literature helped us determine the dependent and independent variables for the study. We took the stress, worry, hopelessness, normality, economic outlook, career outlook, and social life as indicators of emotions as dependent variables. Meanwhile, optimism, preparedness, emotional resilience, spiritualism, positive involvement, entertainment, avoidance, and social support were identified as independent variables. We tested whether there were changes in behaviour during COVID-19 pandemic in terms of dependent variables. We also tested whether there were adverse changes in behaviour during COVID-19 pandemic in terms of dependent variables. In addition, we examined the relationship between independent and dependent variables. Finally, we tested whether controlling adverse behaviour with the help of independent variables can bring normalcy to the behaviour.

To achieve our objectives, we employed regression analysis through GMM and LOGIT regression. Regression analysis through GMM pointed out avoidance, optimism, preparedness, emotional resilience, and social support as effective factors to control behaviour, and these are ranked as per the order of their occurrence, i.e. avoidance as rank 1, optimism as rank 2 , and so on. Results from running LOGIT regression revealed that career outlook and negative emotions as a whole are key for returning to normal behaviour. In addition, career outlook was found to be related to financial well-being, and 
controlling the emotions in respect of the career outlook can result in the normalcy of behaviour. The importance of financial well-being in underdeveloped countries was also duly recognized by Mahendru et al. (2020). Through LOGIT regression, we also found emotional resilience, social support, and avoidance to be the effective factors to control behaviour, and these were ranked as per the order of their occurrence, i.e. emotional resilience as rank 1, social support as rank 2, and avoidance as rank 3. However, contrary to GMM regression results, preparedness and optimism were not found to be significant employing LOGIT regression.

Our findings revealed that emotional resilience, social support, and avoidance are significant in returning to normalcy. Out of these, emotional resilience was identified as the most important factor for controlling negative emotions and returning to normalcy. Moreover, emotional resilience was found to be least significant in pre-COVID times but most significant during the pandemic. Social support was found to be a crucial factor to control adverse changes in emotions which in turn can help bringing the behaviour to normalcy during the pandemic. In addition, avoiding thoughts and news related to the pandemic was found to be the most effective factor to control negative emotions and would also help in bringing the behaviour to normalcy during the pandemic. It is often seen that misinfodemics often lead to negative emotions, and therefore avoiding such misinfodemics leads to control of negative emotions. Sharma et al. (2020) also point out the importance of avoidance of misinfodemics during COVID-19 pandemic. Our analysis did not indicate preparedness as an effective factor in controlling negative emotions. This confirms that though preparedness may prevent the risk of COVID-19 infection, it is not important in bringing the behaviour back to normalcy. Optimist was found to be an important (rank 2) factor in controlling emotions employing GMM regression but was found to be insignificant employing LOGIT regression. This implies that though optimism is significant for controlling emotions in general, it does not help to bring the behaviour to normalcy during the pandemic.

Researchers and academicians may benefit from the novel methodology employed in this study. Employing both GMM and LOGIT regression simultaneously, we could limit the numbers of independent variables to 3 most important variables, i.e. emotional resilience, social support, and avoidance. Our study has paved the way towards a novel quantified approach in psychological studies which can present robust and reliable mechanisms to analyse psychological dimensions. Future researchers may replicate our approach to extend this research direction in controlling negative emotions and perceptions regarding COVID-19 vaccination.

Governments may also take the results of the study into account while devising policies related to well-being of individuals during the pandemic. The policies towards this goal may stress emotional resilience, social support, and avoidance which were found to be effective in bringing the behaviour to normalcy.

The role of social institutions is also crucial in providing social support and ensuring emotional resilience during the pandemic. These social institutions may also take these results into account while providing their services.

The study is not free of limitation. The data for the study has been collected through the electronic source, i.e. Google Forms. This limits the data for only those individuals who have the means and capabilities of using Google Forms. This may also negatively impact the reliability of the data collected. In addition, we attempted to quantify some subjective data which could also affect the robustness of our results.

Author contribution Vishal Pandey: Writing, data collection, and review Amogh Talan: Writing draft, conclusion, revision, English corrections, and discussion

Mandeep Mahendru: Introduction, methods, and data analysis

Umer Shahzad: Review, concept, supervision, and literature review

Data Availability The datasets used during the current study are available from the corresponding or first author on reasonable request.

\section{Declarations}

Ethics approval and consent to participate Not applicable

Consent for publication Not applicable

Competing interests The authors declare no competing interests.

\section{References}

Ahorsu, D. K. et al. (2020) 'The Fear of COVID-19 Scale: Development and Initial Validation', International J Mental Health Addict. https:// doi.org/10.1007/s11469-020-00270-8

Atsushi OSIIIO, Naka M, Kaneko H (2002) Development and validation of an adolescent resilience scale. Jpn J Couns Sci 35:57-65

Beck AT et al (1974) "The measurement of pessimism: the hopelessness scale.” J Consult Clin Psych 42(6):861-5. https://doi.org/10.1037/ h0037562

Behar E, Dobrow I, Hekler EB, Mohlman J, Staples AM (2009) Current theoretical models of generalized anxiety disorder (GAD): conceptual review and treatment implications. J Anxiety Disord 23(8): 1011-1023. https://doi.org/10.1016/j.janxdis.2009.07.006

Biswas M (2011) South Asian. South Asian J Manag 18(4):90-120. https://doi.org/10.32388/8054gt

Brooks SK, Webster RK, Smith LE, Woodland L, Wessely S, Greenberg N, Rubin GJ (2020) The psychological impact of quarantine and how to reduce it: rapid review of the evidence. Lancet 395(20) Elsevier Ltd:912-920. https://doi.org/10.1016/S0140-6736(20) 30460-8

Chatterjee D, Chattopadhyay A (2019) Binary logistic regression modeling in predicting consumer behavior towards mutual fund investment. Asian J Managerial Sci 8(1):59-65 
Cortina JM (1993) What is coefficient alpha ? An examination of theory and applications. J Appl Psychol 78(1):98-104

Davenport TO (2015) Does digital media use increase stress? World Economic Forum. Retrieved from May 2021, https://www. weforum.org/agenda/2015/09/does-digital-media-use-increasestress/

Dennison Himmelfarb CR, Baptiste D (2020) Coronavirus disease (COVID-19). J Cardiovasc Nurs 35:318-321. https://doi.org/10. 1097/jen.0000000000000710

Doğan B, Ben Jebli M, Shahzad K, Farooq TH, Shahzad U (2020) Investigating the effects of meteorological parameters on COVID19: case study of New Jersey, United States. Environ Res 191: 110148. https://doi.org/10.1016/j.envres.2020.110148

Dougall AL, Hyman KB, Hayward MC, Sheila Mcfeeley AAB (2001) Optimism and traumatic stress : the importance of social support and coping1. J Appl Soc Psychol 31(2):223-245

Fareed Z, Iqbal N, Shahzad F, Shah SGM, Zulfiqar B, Shahzad K, Hashmi SH, Shahzad U (2020) 'Co-variance nexus between COVID-19 mortality, humidity, and air quality index in Wuhan, China: new insights from partial and multiple wavelet coherence', Air Quality. Atmosphere and Health 13(6):673-682. https://doi.org/ 10.1007/s11869-020-00847-1

Fornell C, Larcker DF (1981) 'Structural equation models with unobservable variables and measurement error: algebra and statistics'. J Mark Res 18(3):382-388. https://doi.org/10.2307/3150980

Fredrickson BL, Tugade MM, Waugh CE, Larkin GR (2003) What good are positive emotions in crises? a prospective study of resilience and emotions following the terrorist attacks on the United States on September 11th , 2001. J Pers Soc Psychol 84(2):365-376. https:// doi.org/10.1037/0022-3514.84.2.365

Frenkel MO, Giessing L, Egger-Lampl S, Hutter V, Oudejans RRD, Kleygrewe L, Jaspaert E, Plessner H (2021) The impact of the COVID-19 pandemic on European police officers: stress, demands, and coping resources. J Crim Just 72:101756. https://doi.org/10. 1016/j.jcrimjus.2020.101756

Hasher L, Goldstein D, Toppino T (1977) Frequency and the conference of referential validity. J Verbal Learn Verbal Behav 16(1):107-112. https://doi.org/10.1016/S0022-5371(77)80012-1

Hofer MA, Wolff CT, Friedman SB, Mason JW (1974) A psychoendocrine study of bereavement: I. 17 hydroxycorticosteroid excretion rates of parents following death of their children from leukemia. Psychosom Med 34:481-491. https:// doi.org/10.1097/00006842-197211000-00001

Holahan C, Rudolf H, Bonin L (1997) Social support, coping, and psychological adjustment: a resources model. In: Sourcebook of social support and personality. Springer, Boston, pp 169-186

Iqbal N, Fareed Z, Shahzad F, He X, Shahzad U, Lina M (2020) The nexus between COVID-19, temperature and exchange rate in Wuhan city : new findings from partial and multiple wavelet coherence. Sci Total Environ 729:138916. https://doi.org/10.1016/j. scitotenv.2020.138916

Jain M, Sharma GD, Mahendru M (2019) Can i sustain my happiness? A review, critique and research agenda for economics of happiness. Sustainability (Switzerland) 11(22):6375. https://doi.org/10.3390/ su11226375

Kar N, Kar B, Kar S (2021) Stress and coping during COVID-19 pandemic: result of an online survey. Psychiatry Res 295(January): 113598

Khafi TY, Yates TM, Luthar SS (2014) Ethnic differences in the developmental significance of parentification. Fam Process 53:267-287. https://doi.org/10.1111/famp.12072

Lazarus RS (1985) The psychology of stress and coping. Issues Ment Heal Nurs 7(1-4):399-418. https://doi.org/10.3109/ 01612848509009463

Mahendru M., Sharma GD., \& Hawkins M. (2020). Toward a new conceptualization of financial well-being. J Pub Affair, e2505.
Masten ANNS, Best KM, Garmezy N (1991) Resilience and development : contributions from the study of children who overcome adversity. Dev Psychopathol 2(4):425-444

Mathijsen FP (2012) Adolescents and spiritualism : is this a good way to cope with fear? A qualitative approach. Ment Health Relig Cult 15(October 2014):37-41. https://doi.org/10.1080/13674676.2011. 585458

Millar EB, Singhal D, Vijayaraghavan P, Seshadri S, Smith E, Dixon P, Humble S, Rodgers J, Sharma AN (2021) Health anxiety, coping mechanisms and COVID 19: an Indian community sample at week 1 of lockdown. PLoS One 16(4 April):e0250336. https://doi.org/10. 1371/journal.pone.0250336

Misra S (2020) Most suicide helplines are of little help as they don't work when people need them. The Print. https:/theprint.in/health/mostsuicide-helplines-are-of-little-help-as-they-dont-work-whenpeople-need-them/442287/. Accessed 16 May 2021

Morgan CA, Southwick S (2014) Perspective: I believe what I remember, but it may not be true. In: Neurobiology of Learning and Memory, vol 112, pp 101-103. https://doi.org/10.1016/j.nlm.2013.12.011

Nagraj A (2012) Holistic view of human behaviour (First). Institute of Advanced Studies in Education (IASE), Sardarshahar

OECD (2020) Policy Responses to Coronavirus (COVID-19), The impact of the coronavirus (COVID-19) crisis on development finance; from https://www.oecd.org/coronavirus/policy-responses/theimpact-of-the-coronavirus-covid-19-crisis-on-developmentfinance-9de00b3b/. Accessed April 202021

Paul C, Matthews M (2017) The Russian "Firehose of Falsehood" Propaganda model: why it might work and options to counter it perspecitves (pp. 16): Rand Corporation. Retrieved from http:// www.rand.org/pubs/perspectives/PE198.html

Peterson C, Bossio LM (1991) Health and optimism. American Psychological Association, Free Press, New York

Piedmont RL, Leach MM (2002) Cross-cultural generalizability of the Spiritual Transcendence Scale in India: Spirituality as a universal aspect of human experience. Am Behav Sci 45(12):1888-1901

Polizzi C, Lynn SJ, Perry A (2020) Stress and coping in the time of COVID-19: pathways to resilience and recovery. Clin Neuropsychiatry 17(2):59-62

Prestin A, Nabi R (2020) Media prescriptions: exploring the therapeutic effects of entertainment media on stress relief, illness symptoms, and goal attainment. J Commun 70(2):145-170. https://doi.org/10.1093/ joc/jqaa001

Reich JW (2006) Three psychological principles of resilience in natural disasters. Disaster Prev Manag 15(5):793-798. https://doi.org/10. 1108/09653560610712739

Rishi P, Acharya S, Das S, Sood A (2021) Varying psychological impacts of COVID-19 and functional/dysfunctional coping strategies: a mixed-method approach. J Health Manag 23(2):226-239. https:// doi.org/10.1177/09720634211011562

Saey TH (2020) COVID-19 may be most contagious one to two days before symptoms appear | Science News. Science News. https:// www.sciencenews.org/article/coronavirus-covid-19-infectioncontagious-days-before-symptoms-appear?utm_source= email\&utm_medium=email\&utm_campaign=latest-newsletterv2\&utm_source $=$ Latest_Headlines\&utm_medium $=$ email\&utm campaign=Latest_Headlines. Accessed April 16, 2021

Sarwar S et al. (2021) 'A study on the effects of meteorological and climatic factors on the COVID-19 spread in Canada during 2020', J Environ Health Sci Eng. https://doi.org/10.1007/s40201-02100707-9

Scheier MF, Carver CS, Bridges MW (1994) Distinguishing optimism from neuroticism (and trait anxiety, self-mastery, and self-esteem): a reevaluation of the life orientation test. J Pers Soc Psychol 67(6): 1063-1078

Shahzad F, Shahzad U, Fareed Z, Iqbal N, Hashmi SH, Ahmad F (2020a) Asymmetric nexus between temperature and COVID-19 in the top 
ten affected provinces of China: a current application of quantile-onquantile approach. Sci Total Environ 736:139115. https://doi.org/ 10.1016/j.scitotenv.2020.139115

Shahzad K, Shahzad U, Iqbal N, Shahzad F, Fareed Z (2020b) Effects of climatological parameters on the outbreak spread of COVID-19 in highly affected regions of Spain. Environ Sci Pollut Res 27(31): 39657-39666. https://doi.org/10.1007/s11356-020-10551-3

Shahzad K et al (2021) Does environmental quality and weather induce COVID-19: Case study of Istanbul, Turkey. Environ Forensic, 0(0): 1-12. https://doi.org/10.1080/15275922.2021.1940380

Shakoor A, Chen X, Farooq TH (2020) 'Fluctuations in environmental pollutants and air quality during the lockdown in the USA and China: two sides of COVID-19 pandemic', Air Quality. Atmos Health 13:1335-1342. https://doi.org/10.1007/s11869-020-00888-6

Shamblaw AL, Rumas RL, Best MW (2021) Coping during the COVID19 pandemic: relations with mental health and quality of life. Can Psychol/Psychologie Canadienne 62(1):92-100. https://doi.org/10. 1037/cap0000263

Sharma GD, Mahendru M (2020) Lives or livelihood: insights from locked-down India due to COVID19. Soc Sci Humanit Open 2(1): 100036. https://doi.org/10.1016/j.ssaho.2020.100036

Sharma GD, Talan G, Jain M (2020) Policy response to the economic challenge from COVID-19 in India: A qualitative enquiry. J Public Aff 20(4). https://doi.org/10.1002/pa.2206

Strelau J, Jaworowska A, Wrzesniewski K, Szczepaniak P (2020) Coping inventory for stressful situations CISS. Psychological Test Lab, Warszawa, p 2020

Swaminathan S (2013) Albert Einstein and Thiruvalluvar. SpeakingTree. https://www.speakingtree.in/blog/albert-einstein-and-thiruvalluvar. Accessed 17 May 2021
Taylor S, Landry CA, Paluszek MM, Fergus TA, Mckay D, Asmundson GJG (2020) Development and initial validation of the COVID stress scales. J Anxiety Disord 72:1-7. https://doi.org/10.1016/j.janxdis. 2020.102232

Ullah S, Akhtar P, Zaefariand G (2018) Dealing with endogeneity bias: the generalized method of moments (GMM) for panel data. Ind Mark Manag 71:69-78

Winefield HR, Winefield AH, Tiggemann M (2010) Social support and psychological well- being in young adults : the multi-dimensional support scale. J Pers Assess 58(1):198-210. https://doi.org/10.1207/ s15327752jpa5801

Worldmeter.com (2021) COVID-19 coronavirus pandemic. World Health Organization, Accessed on May 20, (2021) from Geneva https://www.worldometers.info/coronavirus/

Yan Y, Shah MI, Sharma GD et al (2021) Can tourism sustain itself through the pandemic: nexus between tourism, COVID-19 cases and air quality spread in the 'Pineapple State' Hawaii. Curr Issues Tour 0:1-20. https://doi.org/10.1080/13683500.2021.1965553

Yıldırım M, Akgül Ö, Geçer E (2021) The effect of COVID-19 anxiety on general health: the role of COVID-19 coping. Int J Ment Heal Addict p 1-12. https://doi.org/10.1007/s1 1469-020-00429-3

Yong AG, Pearce S (2013) A Beginner's guide to factor analysis: focusing on exploratory factor analysis. Tutor Quant Methods Psychol 9(2):79-94

Publisher's note Springer Nature remains neutral with regard to jurisdictional claims in published maps and institutional affiliations. 